Int. J. Electrochem. Sci., 14 (2019) $6123-6132$

International Journal of

ELECTROCHEMICAL

SCIENCE

WWW.electrochemsci.org

\title{
Phosphorous Modified Metal Boride as High Efficiency HER Electrocatalyst
}

Yiteng Liu, Jian Zhang, Xianxian Li, Zhaowei Zeng, Xu Cheng, Yadong Wang ${ }^{*}$, and Mu Pan

State Key Laboratory of Advanced Technology for Materials Synthesis and Processing, Wuhan University of Technology, Wuhan 430070, China

*E-mail: ywang@whut.edu.cn

doi: $10.20964 / 2019.07 .68$

Received: 9 March 2019 / Accepted: 10 May 2019 / Published: 10 June 2019

The investigation on highly active and durable electrocatalysts for the hydrogen evolution reaction (HER) is of great significant for renewable energy technologies. Herein, we report the fabrication of a series of amorphous $\mathrm{Co}_{10-\mathrm{x}}-\mathrm{Ni} \mathrm{i}_{\mathrm{x}} \mathrm{B}-\mathrm{P}$ nanocomposites via a facile chemical reduction and phosphorization method. Compared to the Ni-B-P, Co-B-P, and other $\mathrm{Co}_{10-\mathrm{x}}-\mathrm{Ni}_{\mathrm{x}}-\mathrm{B}-\mathrm{P}$ electrodes, the Co8.5-Ni ${ }_{1.5}$-B-P nanocomposite catalyst exhibited the highest HER electrocatalytic activity in alkaline solution. The overpotential of Co ${ }_{8.5}-\mathrm{Ni}_{1.5}-\mathrm{B}-\mathrm{P}$ is $145 \mathrm{mV}$ at a current density of $10 \mathrm{~mA} \mathrm{~cm} \mathrm{~cm}^{-2}$, and a low Tafel slope of $60.5 \mathrm{mV} \mathrm{dec}^{-1}$ is realized. $\mathrm{Co}_{8.5}-\mathrm{Ni}_{1.5}-\mathrm{B}-\mathrm{P}$ also exhibits superior durability, showing no obvious degradation after 50 hours. These new phosphorous-modified borides are proved to be a new low-cost and high-efficiency catalyst system for water splitting.

Keywords: Boride, hydrogen evolution reaction, phosphide, HER catalyst, water splitting

\section{FULL TEXT}

(C) 2019 The Authors. Published by ESG (www.electrochemsci.org). This article is an open access article distributed under the terms and conditions of the Creative Commons Attribution license (http://creativecommons.org/licenses/by/4.0/). 